\title{
Razlaga pravnih pravil s pomočjo propozicijske logike - primer družinskih prejemkov
}

\author{
UDK: 340:004.8 \\ Iztok Rakar \\ Univerza v Ljubljani, Fakulteta za upravo \\ iztok.rakar@fu.uni-lj.si \\ Domen Cukjati \\ Univerza v Ljubljani, Fakulteta za upravo \\ domen.cukjati@fu.uni-lj.si
}

\section{IZVLEČEK}

Pogost vir dvoumnosti ter nejasnosti v pravnih besedilih je navajanje pogojev, ki določajo, ali nekomu določena pravica pripada ali ne. Problematični so primeri, ko je navedenih več obligatornih in opcijskih pogojev, po možnosti deloma zapisanih $v$ trdilni in deloma $v$ nikalni obliki. Namen tega prispevka je na primeru 47. člena "Pravilnika o postopkih za uveljavljanje pravic do družinskih prejemkov" (Ur.I. RS, št. 31/2008) pokazati, da lahko za sistematično dokazovanje vsebinske (ne)smiselnosti določene strukture pogojev uporabimo propozicijsko logiko. V prispevku najprej zapišemo besedilo 47. člena s sintakso propozicijske logike, poiščemo vse možne interpretacije besedila, med njimi izberemo vse, ki predstavljajo logično pravilne, vendar logično različne izjave, ter za vsako od njih preverimo ali predstavlja semantično smiselno formulacijo. Na ta način dokažemo, da je sedanja formulacija besedila zapisana dvoumno ter vsebinsko nesmiselno. Na koncu prispevka podamo splošno priporočilo za navajanje pogojev, predlagamo nedvoumno obliko zapisa besedila ter pokažemo, kakšne so v praksi posledice zaradi napačne formulacije pogojev.

Ključne besede: umetna inteligenca v pravu, propozicijska logika, semantična smiselnost pogojev, pravna država, socialna država.

\section{Uvod}

Pravo je eno od primernejših področij za uporabo umetne inteligence tudi v praksi, saj je načeloma vse določeno s pravnimi pravili in predpisi (Tomažič, 2008). Razvoj računalniške tehnologije je prišel do stopnje, ko bi se lahko zgradilo $v$ praksi uporabne sisteme umetne inteligence tudi na področju prava 
Iztok Rakar, Domen Cukjati

Razlaga pravnih pravil s pomočjo propozicijske logike primer družinskih prejemkov

(Love \& Genesereth, 2005). Razvoj discipline "umetna inteligenca v pravu« se $\checkmark$ akademskih vodah opaža že nekaj časa, kar se vidi po številu konferenc ${ }^{\boldsymbol{1}}$ in člankov ${ }^{\mathbf{2}}$, inštitutih in združenjih, npr. IAAIL ${ }^{\mathbf{3}}, \mathbf{v}$ zadnjem času pa so se na tem področju pojavila še komercialna razvojno-raziskovalna podjetja, kot je npr. Alin-Law Future Technologies Inc. ${ }^{4}$.

Pri razvoju uporabnega inteligentnega sistema je treba preseči kar nekaj preprek in težav, od tehnoloških do vsebinskih. Med slednje spada jasno in nedvoumno izražanje $v$ pravnih besedilih, $s$ čimer se omogoči uporabo kakšne od formalnih logik, o čemer je pisal že Layman (Layman, 1957). Ker pa v pravu obstaja tudi del, ki je in bo vedno ostal predmet interpretacij, ker je odvisen od situacij $\vee$ realnem življenju, se niti $\vee$ teoriji vsega prava ne da prevesti na enostavno uporabo pravila "modus ponens" (Rissland et al, 2003). Zato je še toliko bolj pomembno, da se jasno in nedvoumno izražanje uporablja tam, kjer se to pač da. Eno od takih področij, kjer je vedno mogoča in zaželena nedvoumna in jasna formulacija besedila, je sestavljanje pogojev, ki določajo, kdaj je nekdo upravičen do določene pravice in kdaj ne.

Pogost vir nejasnosti pri navajanje pogojev so primeri, ko so $v$ enem stavku navedeni tako obligacijski kot opcijski pogoji, po možnosti deloma zapisani $\vee$ trdilni in deloma $\vee$ nikalni obliki, kar lahko vodi do večjega števila možnih interpretacij. Najtrši oreh pa so primeri, ko so vse interpretacije, poleg tega, da jih je več, še vsebinsko nesmiselne. Primer takšne formulacije je 47. člen Pravilnika o postopkih za uveljavljanje pravic do družinskih prejemkov ( $v$ nadaljevanju 47. člen) ${ }^{\mathbf{5}}$ :

"Če eden od vzdrževalcev družine izgubi zaposlitev in ne prejema nadomestila, a je prijavljen $v$ evidenci Zavoda Republike Slovenije za zaposlovanje kot brezposeln ali ne prejema pokojnine ali delnega plačila za izgubljeni dohodek, se njegovi dohodki iz bruto plač $\vee$ preteklem letu ne vštevajo $\vee$ skupni dohodek družine."

Ta člen različni pravni strokovnjaki različno interpretirajo, nekaterim pa se zdi formulacija celo napačna oz. vsebinsko nesmiselna.

1 http://www.iaail.org/index.html.

$2 \mathrm{http}: / /$ www.leibnizcenter.org/publications.

3 IAAIL - International Association for Artificial Intelligence and Law. http://www.iaail.org/.

$4 \mathrm{http}: / /$ www.ai-in-law.com.

5 Pravilnik o postopkih za uveljavljanje pravic do družinskih prejemkov, Ur.I. RS, št. 31/2008. 
Za nadaljnji razvoj umetne inteligence $v$ pravu bi bilo uporabno, če bi imeli orodje, s katerim bi lahko na sistematičen način odkrivali dvoumnosti, jih dokazovali ter predlagali nedvoumne formulacije besedil. Tako orodje pa bi pomagalo tudi krepiti uveljavitev načela pravne države, kajti vsebinska jasnost pravil je sestavni del pravne varnosti, ta pa je sestavni del pravne države /Sachs (ur.), 2003, str. 850, r. št. 125)..$^{6}$ Nejasna vsebina pravil namreč omogoča arbitrarnost in zlorabe ${ }^{7}$, kar je $v$ nasprotju z načelom pravne države in ima lahko hude posledice za nosilce pravic, še posebej na socialnem področju.

Namen tega prispevka je na primeru 47. člena pokazati, da lahko za sistematično dokazovanje vsebinske (ne)smiselnosti določene strukture pogojev uporabimo propozicijsko logiko, ki vključuje zapis besedila s sintakso propozicijske logike, sklepanje s pomočjo njenih pravil ter uporabo tehnike logične dekompozicije. $^{\boldsymbol{s}}$

Metoda reševanja (poglavje 2) vključuje zapis 47. člena s sintakso propozicijske logike ter iskanje vseh možnih interpretacij. ${ }^{\boldsymbol{9}}$ Nato med njimi $\mathrm{s}$ pomočjo pravil propozicijske logike poiščemo vse logično različne kombinacije oklepajev ter za vsako od njih preverimo ali predstavlja vsebinsko smiselno formulacijo, pri čemer si pomagamo s tehniko logične dekompozicije. Rezultat reševanja (poglavje 4) so dokazane trditve, da je sedanja formulacija 47 . člena dvoumna, da v vseh možnih interpretacijah definira vsaj en pogoj na način, da je ta pogoj brez funkcije ter da si pri analizi vsebinske smiselnosti formulacije postavljenih pogojev lahko pomagamo s propozicijsko logiko. $V$ diskusiji (poglavje 5) razmišljamo o vzrokih za različne interpretacije ter mehanizmu napačnega intuitivnega sklepanja. Nato podamo splošno priporočilo za navajanje pogojev pri pisanju pravnih besedil ter predlagamo semantično smiselno obliko 47. člena. Na koncu si pogledamo še, kako 47. člen $v$ praksi interpretira pristojno ministrstvo in kakšne so posledice.

6 Jasnost pravnih pravil je eden od elementov načela pravne države, ki ga slovenska ustava ne ureja izrecno, na ustavno raven pa ga je dvignila sodna praksa Ustavnega sodišča Republike Slovenije Šturm (ur.) (2002, str. 55, r. št. 4Ć. Gl. npr. odločbo Ustavnega sodišča RS, št. U-I-220/03-20 z dne 13. 10. 2004.

7 Več o tem Rakar (2006).

8 Podr. o logiki v pravu Schneider (1999 / 1991).

$9 \mathrm{~V}$ prispevku se ne bomo ukvarjali z morebitno neskladnostjo med določbami pravilnika in zakona, na podlagi katerega je bil izdan. 
Iztok Rakar, Domen Cukjati

Razlaga pravnih pravil s pomočjo propozicijske logike -

primer družinskih prejemkov

\section{Analiza pogojev s pomočjo propozicijske logike}

\subsection{Teoretično orodje}

\subsubsection{Propozicijska logika}

Propozicijska (tudi propozicionalna oz. po slovensko stavčna ali izjavna) logika je logika, ki opisuje in normira sklepalna razmerja med stavki oz. izjavami, ki jih imenujemo tudi propozicije. Propozicijska logika nas zanima, ker lahko vanjo prevajamo argumente in $v$ formalnem jeziku preučujemo njihovo veljavnost. Tisto, kar nastane po prevodu dejanskega argumenta, je samo zaporedje osnovnih izjav oz. sestavljena izjava. Pri tem uporabljamo sintakso, ki vsebuje črke $p, q, r, \ldots$ za zapis izjav, pet klasičnih veznikov: negacija (!), konjunkcija ( $\wedge$ ), disjunkcija $(\vee)$, implikacija $(\rightarrow)$ in ekvivalenca $(\Leftrightarrow)$, oklepaje $»()$ ) ter naslednja pravila (Šuster, 2000, Mendelson, 1997):

\begin{tabular}{|c|c|c|c|c|c|c|c|c|}
\hline \multirow{6}{*}{\multicolumn{3}{|c|}{$\begin{array}{l}\text { Prioritetna vrsta za vezni- } \\
\text { ke ter oklepaje: } \\
((), !, \wedge, \vee, \rightarrow, \Leftrightarrow\end{array}$}} & \multirow{2}{*}{\multicolumn{3}{|c|}{$\begin{array}{l}\text { Negacija pravilno oblikova- } \\
\text { nega izraza a, !a je res- } \\
\text { nična, če in samo če je p } \\
\text { neresničen. } \\
\qquad \begin{array}{l}\text { a } \\
\text { a }\end{array}\end{array}$}} & \multicolumn{3}{|c|}{$\begin{array}{l}\text { Konjunkcija je resnična, če } \\
\text { sta oba člena konjunkcije } \\
\text { resnična in neresnična v } \\
\text { vseh drugih primerih. }\end{array}$} \\
\hline & & & & & & a & $b$ & $a \wedge b$ \\
\hline & & & & R & $N$ & R & $\mathrm{R}$ & $\mathrm{R}$ \\
\hline & & & & $\mathrm{N}$ & $\mathrm{R}$ & $\mathrm{R}$ & $\mathrm{N}$ & $\mathrm{N}$ \\
\hline & & & \multirow{2}{*}{\multicolumn{3}{|c|}{ (R-resničen, N-neresničen) }} & $\mathrm{N}$ & $\mathrm{R}$ & $\mathrm{N}$ \\
\hline & & & & & & $\mathrm{N}$ & $\mathrm{N}$ & $\mathrm{N}$ \\
\hline \multicolumn{3}{|c|}{$\begin{array}{l}\text { Disjunkcija je neresnična, } \\
\text { če sta oba člena disjunkci- } \\
\text { je neresnična in resnična } \\
\text { v vseh drugih primerih. }\end{array}$} & \multicolumn{3}{|c|}{$\begin{array}{l}\text { Implikacija je neresnična, } \\
\text { če je antecedens resničen, } \\
\text { konsekvens pa neresničen } \\
\text { in resnična v vseh drugih } \\
\text { primerih. }\end{array}$} & \multicolumn{3}{|c|}{$\begin{array}{l}\text { Ekvivalenca je resnična, če } \\
\text { sta oba člena resnična in } \\
\text { oba člena neresnična in } \\
\text { neresnična v vseh drugih } \\
\text { primerih. }\end{array}$} \\
\hline a & b & $a \vee b$ & a & b & $a \rightarrow b$ & a & b & $a \Leftrightarrow b$ \\
\hline R & $\mathrm{R}$ & R & $\mathrm{R}$ & $\mathrm{R}$ & $\mathrm{R}$ & R & R & R \\
\hline R & $\mathrm{N}$ & R & R & $N$ & $\mathrm{~N}$ & R & $N$ & $\mathrm{~N}$ \\
\hline $\mathrm{N}$ & $\mathrm{R}$ & $\mathrm{R}$ & $\mathrm{N}$ & $\mathrm{R}$ & $\mathrm{R}$ & $\mathrm{N}$ & $\mathrm{R}$ & $\mathrm{N}$ \\
\hline $\mathrm{N}$ & $\mathrm{N}$ & $N$ & $N$ & $N$ & R & $\mathrm{N}$ & $\mathrm{N}$ & $\mathrm{R}$ \\
\hline
\end{tabular}


Iz predstavljenih pravil lahko izpeljemo nova pravila, med katerimi bomo pri našem delu potrebovali pravili distribucije:

$$
\begin{aligned}
& c \wedge(a \vee b) \rightarrow(c \wedge a) \vee(c \wedge b), \\
& c \vee(a \wedge b) \rightarrow(c \vee a) \wedge(c \vee b),
\end{aligned}
$$

pravili asociativnosti:

$$
\begin{aligned}
& ((a \wedge b) \wedge c) \rightarrow(a \wedge(b \wedge c)) \Leftrightarrow(a \wedge b \wedge c), \\
& ((a \vee b) \vee c) \rightarrow(a \vee(b \vee c)) \Leftrightarrow(a \vee b \vee c)
\end{aligned}
$$

ter De Morganova teorema:

$$
\begin{aligned}
& !(a \wedge b) \rightarrow ! a \vee ! b, \\
& !(a \vee b) \rightarrow ! a \wedge ! b .
\end{aligned}
$$

\subsubsection{Logična dekompozicija}

Kadar želimo za kakšno kompleksnejše sestavljeno izjavo poiskati vse kombinacije vrednosti osnovnih izjav, ki povzročijo, da je sestavljena izjava resnična, naredimo tabelo resničnosti. Vendar pri tem velikost tabele hitro narašča, ker število kombinacij narašča kot $2^{n}$, pri čemer je $n$ število izjav. Tako npr. za sestavljeno izjavo, ki je sestavljena iz 7-ih enostavnih izjav, dobimo tabelo z $\mathbf{2}^{\mathbf{7}}=128$ vrsticami ter 8 stolpci.

Logična dekompozicija je hitrejši način, ki nam z manj truda vrne vse kom-

\begin{tabular}{|c|c|c|c|}
\hline $\begin{array}{c}a \wedge b \\
l \\
a \\
b\end{array}$ & $\begin{array}{l}a \vee b \\
/ \backslash \\
a \quad b\end{array}$ & $\begin{array}{l}a \rightarrow b \\
/ \quad \backslash \\
! a \quad a \\
b\end{array}$ & $\begin{array}{ll}a & \Leftrightarrow b \\
/ & l \\
a & ! a \\
b & ! b\end{array}$ \\
\hline $\begin{array}{c}!(a \wedge b) \\
/ \quad \backslash \\
! a \quad b\end{array}$ & $\begin{array}{c}!(a \vee b) \\
\mid \\
! a \\
! b\end{array}$ & $\begin{array}{c}!(a \rightarrow b) \\
\mid \\
a \\
! b\end{array}$ & $\begin{array}{cc}!(a & \Leftrightarrow b) \\
/ & \backslash \\
! a & a \\
b & ! b\end{array}$ \\
\hline
\end{tabular}
binacije vrednosti, ob katerih ima sestavljena izjava vrednost "resnično", izpusti pa kombinacije, ob katerih ima sestavljena izjava vrednost "neresnično«. Sestavljeno izjavo počasi razbijamo na manjše izjave in velja, da kadar ima manjša izjava vrednost »R«, ima tudi izvorna sestavljena izjava vrednost »R«. Pri tem si pomagamo z naslednjimipravili, zapisanimi $\vee$ grafični obliki: 
Iztok Rakar, Domen Cukjati

Razlaga pravnih pravil s pomočjo propozicijske logike -

primer družinskih prejemkov

\subsubsection{Shema osebnih stanj v RS}

Za potrditev semantične (ne)miselnosti 47. člena, moramo poznati dejanske odnose med osebnimi stanji, ki se kot pogoji pojavljajo v 47. členu. Osebna stanja so opredeljena $v$ ustrezni zakonodaji in jih bomo na tem mestu le grafično predstavili:

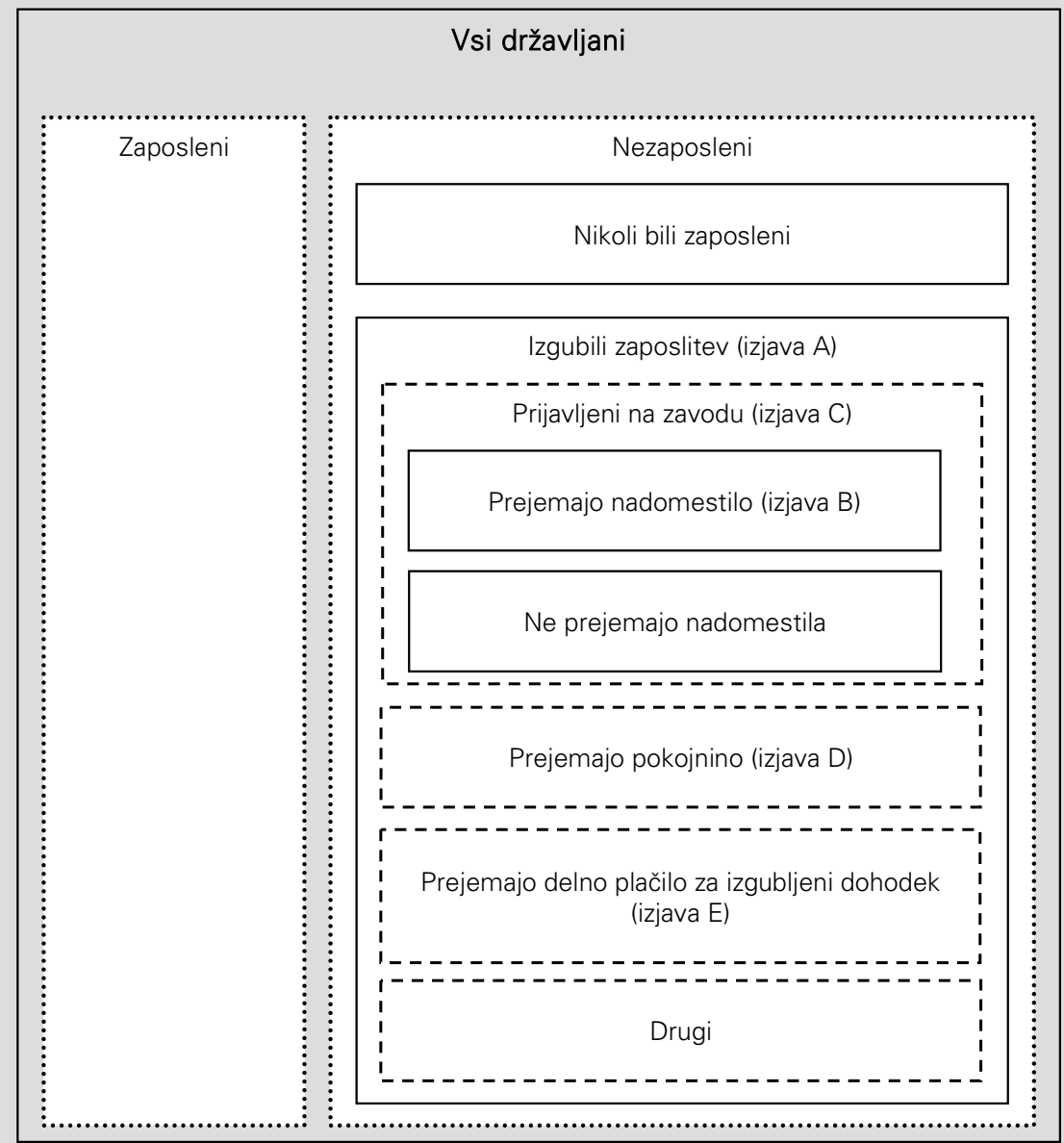

\subsection{Reševanje}

V tem delu bomo na konkretnem primeru 47. člena Pravilnika o postopkih za uveljavljanje pravic do družinskih prejemkov (v nadaljevanju 47. člen), ki je bil predstavljen $\vee$ 1. poglavju, uporabili preverjanje logične resničnosti, logično dekompozicijo ter preverjanje semantične smiselnosti. 


\subsubsection{Zapis 47. člena s sintakso propozicijske logike}

Zapišimo izjave v 47. členu s simboli:

A - »vzdrževalec družine je izgubil zaposlitev«;

B - »vzdrževalec družine prejema nadomestilo«;

C - »vzdrževalec družine je prijavljen v evidenci Zavoda Republike

Slovenije za zaposlovanje kot brezposelna oseba«;

D - »vzdrževalec družine prejema pokojnino«;

E - »vzdrževalec družine prejema delno plačilo za izgubljeni dohodek«;

F - »dohodki vzdrževalca družine iz naslova bruto plač iz preteklega leta se vštevajo v skupni dohodek družine».

Sedaj poizkusimo zapisati 47. člen s sintakso propozicijske logike ter ravnokar definiranih simbolov. Na začetku gre enostavno:

$A \wedge ! B \wedge C \vee ! D \vee ? ? ? ?$

pri besedilu:

"... ali delnega plačila za izgubljeni dohodek, ..."

pa se zatakne, oz. si jo je potrebno natančneje pogledati. To besedilo je od preostalega ločeno na začetku z veznikom "ali in na koncu z vejico, kar nakazuje, da gre za samostojno izjavo. Težava pa je, ker ta del besedila nima povedka, ki pa ga iz konteksta zlahka prepoznamo: "prejemati«. Če pogledamo v celotno besedilo 47. člena, vidimo, da sta $\vee$ njem dva povedka »prejemati«. Eden na začetku kot del izjave $B$ in eden nekje $v$ sredini kot del izjave $D$. Sklepamo, da se naše obravnavano besedilo nanaša na povedek "prejemati « $v$ izjavi D, torej moramo besedilo, ki ga obravnavamo, pogledati $\vee$ povezavi $z$ izjavo D. Če sedaj poizkušamo zapisati izjavi D in E s simboli, naletimo na vsaj tri dokaj mogoče variante oz. interpretacije:

$$
\begin{aligned}
& ! D \vee E \\
& ! D \vee ! E \\
& !(D \vee E) .
\end{aligned}
$$

Katera je pravilna? Ker so zapisane izjave vse logično pravilne, moramo uporabiti semantiko, oz. vsebino izjav $\vee$ konkretnem življenju (interpretacija dejanskega življenja) ter pogledati, katera kombinacija izjav D 
Iztok Rakar, Domen Cukjati

Razlaga pravnih pravil s pomočjo propozicijske logike -

primer družinskih prejemkov

in $E$ je semantično smiselna. Upoštevajmo še, da sta množici D in E disjunktni, oz. da je njun presek prazna množica:

$D \wedge E=\{\}$,

ker po zakonu noben posameznik ne more prejemati pokojnine ter delnega plačila za izgubljeni dohodek hkrati. Tako dobimo:

\begin{tabular}{|l|l|l|l|}
\hline Izjava & Dodaten podatek & Sklep & Komentar \\
\hline$! D \vee E$ & $D \wedge E=\{\}$ & $(! D \vee E) \Leftrightarrow ! D$ & $\begin{array}{l}\text { Pogoj } E \text { je nepotreben, ker je zajet } \\
\text { že } \vee ! D .\end{array}$ \\
\hline$! D \vee ! E$ & $D \wedge E=\{\}$ & $\begin{array}{l}(! D \vee ! E) \Leftrightarrow \\
\text { polna množica« }\end{array}$ & $\begin{array}{l}\text { Na ta način dopustimo prav vse } \\
\text { primerke, torej sta pogoja } D \text { in } E \\
\text { oba nepotrebna. }\end{array}$ \\
\hline$!(D \vee E)$ & $D \wedge E=\{\}$ & $\begin{array}{l}(D \vee E) \Leftrightarrow \\
(! D \wedge ! E)\end{array}$ & $\begin{array}{l}\text { Na ta način zajamemo tiste, ki ne } \\
\text { prejemajo pokojnine in ne prejema- } \\
\text { jo delnega plačila. Skratka, tiste, ki } \\
\text { ne prejemajo dohodka }- \text { katerega- } \\
\text { koli od } D \text { in } E \text {. To pa ima smisel. }\end{array}$ \\
\hline
\end{tabular}

Tudi, če se vprašamo, kaj je namen besedila, ki vključuje izjavi D in $E$, pridemo do sklepa, da je pisec verjetno želel izključiti prejemanje česarkoli. Tako vzamemo za pravilno interpretacijo izjavo:

$!(D \vee E)$.

Tako pridemo do zapisa 47. člena:

$(A \wedge ! B \wedge C \vee !(D \vee E)) \rightarrow(! F)$

Vendar nas ne zanima, kdaj je ta izjava kot celota logično resnična, temveč le, kdaj je pogoj oz. kombinacija pogojev resnična oz. kdaj so pogoji za dodelitev pravice izpolnjeni. Zanima nas torej samo izjava:

$A \wedge ! B \wedge C \vee !(D \vee E)$. 


\subsubsection{Iskanje logično različnih kombinacij oklepajev}

Problem, ki smo ga že omenili je, da pravni strokovnjaki različno interpretirajo kombinacijo pogojev. $Z$ drugo besedo, imajo različna mnenja o tem, kateri pogoji so bolj skupaj kot drugi oz. kje stojijo oklepaji, ki jih $\vee$ pisanem besedilu seveda ni, ampak jih moramo začutiti iz konteksta oz. na kaj se posamezni vezniki "ali« nanašajo ter kaj vse je zanikano in kaj ne. Če smo v prejšnjem poglavju imeli problem, ko je bilo semantično dokaj jasno, kaj je namen izjav $D$ in $\mathrm{E}$ in je bil problem pravilno zapisati besedilo s sintakso propozicijske logike, imamo sedaj obraten problem. Izjave imamo že zapisane, le dodati bi morali pravilno postavljene oklepaje, ki pa so stvar interpretacije in ne sledijo neposredno iz besedila. Da se izognemo neskončnemu prerekanju, katera postavitev je pravilnejša, enostavno zapišimo vse možne postavitve oklepajev:

$$
\begin{array}{lll}
\text { izjava 1) } & (A \wedge ! B \wedge C) \vee !(D \vee E), & \\
\text { izjava 2) } & ((A \wedge ! B) \wedge C) \vee !(D \vee E) & \text { - logično enaka kot izjava 1, } \\
\text { izjava 3) } & (A \wedge(! B \wedge C) \vee !(D \vee E) & \text { - logično enaka kot izjava 1, } \\
\text { izjava 4) } & A \wedge(! B \wedge C \vee !(D \vee E)), & \text { - logično enaka kot izjava 5, } \\
\text { izjava 5) } & A \wedge((B \wedge C) \vee !(D \vee E)) & \\
\text { izjava 6) } & A \wedge(! B \wedge(C \vee !(D \vee E))), & \\
\text { izjava 7) } & (A \wedge ! B) \wedge(C \vee !(D \vee E)) & \text { - logično enaka kot izjava 6, } \\
\text { izjava 8) } & (A \wedge ! B) \wedge C \vee !(D \vee E) & \text { - logično enaka kot izjava 1, } \\
\text { izjava 9) } & A \wedge(! B \wedge C) \vee !(D \vee E) & \text { - logično enaka kot izjava 1, } \\
\text { izjava 10) } & A \wedge ! B \wedge(C \vee !(D \vee E)) & \text { - logično enaka kot izjava 6, } \\
\text { izjava 11) } & A \wedge ! B \wedge C \vee !(D \vee E) & \text { - logično enaka kot izjava 1. }
\end{array}
$$

Sedaj bi morali za vsako od enajstih kombinacij oklepajev preveriti vse možne kombinacije resničnosti izjav $A, B, C, D$ in $E$, kar pomeni $11 \times 2^{5}=0 z$. 352 kombinacij. Da se izognemo časovno potratnemu preverjanju, najprej izločimo vse kombinacije oklepajev, ki so logično enake kot kakšna druga kombinacija $s$ pomočjo pravil asociativnosti. $\vee$ gornjem seznamu smo take izjave označimo z besedilom "logično enaka kot izjava ...". Tako zmanjšamo število logično različnih kombinacij oklepajev na 3 in sicer so to izjave 1, 5 in 6 . Število kombinacij za katere bi morali sedaj preveriti ali naredijo izjavo pogojev resnično se je zmanjšalo na $3 \times 5^{2}=96$. 
Iztok Rakar, Domen Cukjati

Razlaga pravnih pravil s pomočjo propozicijske logike -

primer družinskih prejemkov

\subsubsection{Logična dekompozicija in preveritev semantične smiselnosti}

Logična dekompozicija nam olajša iskanje kombinacij pogojev, ki nam naredijo izjavo pogojev resnično zato, ker nam vrne spisek le tistih kombinacij pogojev, ki nam naredi izjavo pogojev resnično. Na izjavah 1, 5 in 6 uporabimo logično dekompozicijo ter si poglejmo, kaj nam logično resnične izjave pomenijo, če upoštevamo še semantično vrednost izjav A, B, C, D in E. Pogledali si bomo torej, ali nam sicer logično resnične izjave predstavljajo tudi $\vee$ naši konkretni situaciji semantično smiselne izjave:

Ad. izjava 1)

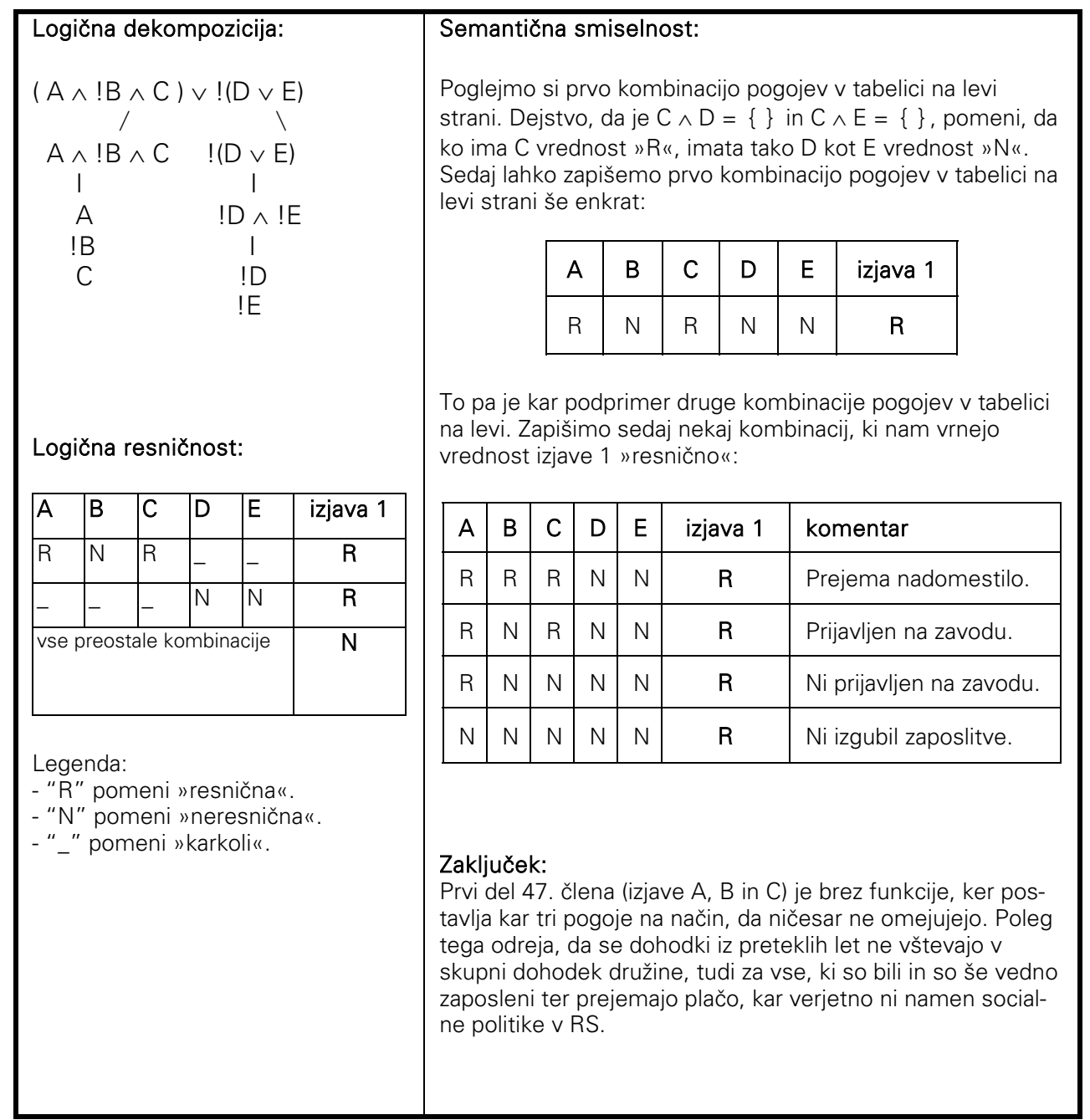


Ad. izjava 5)

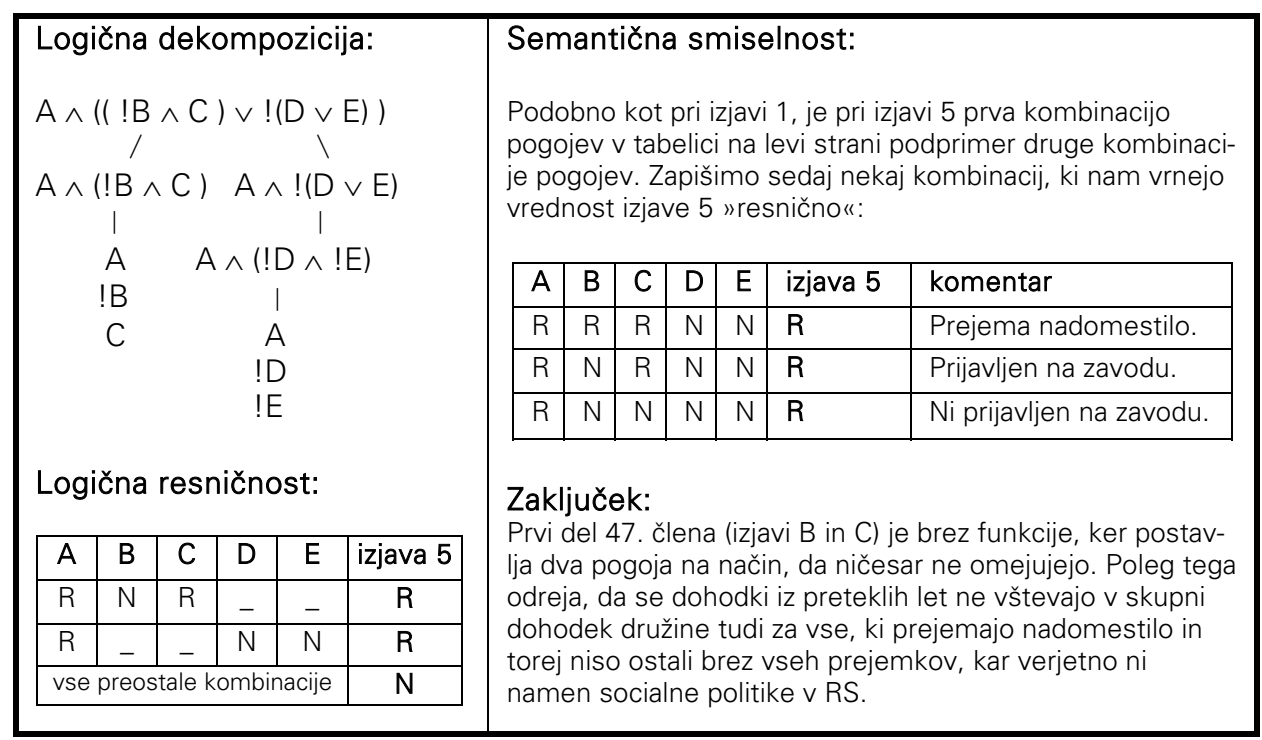

Ad. izjava 6)

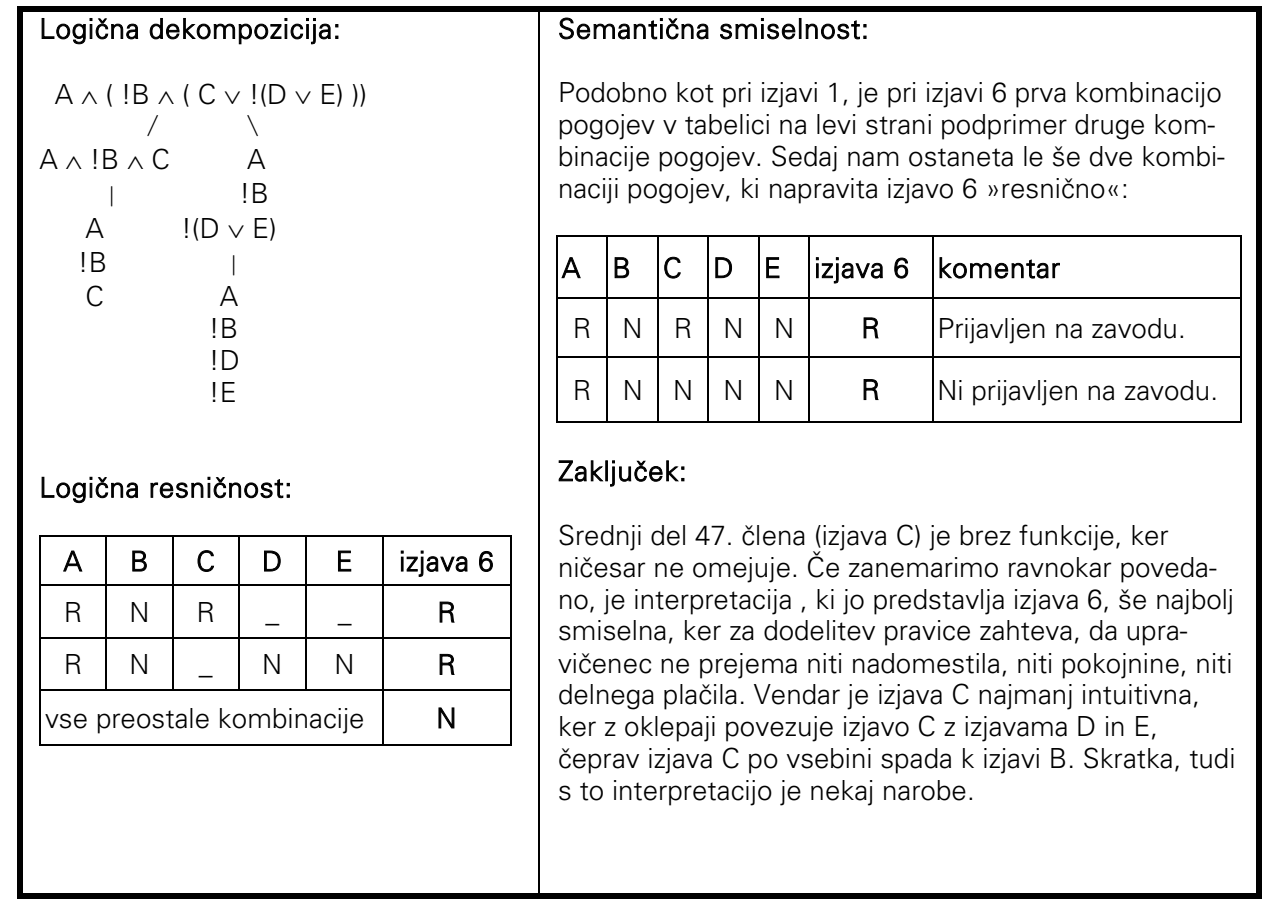


Iztok Rakar, Domen Cukjati

Razlaga pravnih pravil s pomočjo propozicijske logike -

primer družinskih prejemkov

\section{Rezultati}

Preko podrobne analize 47. člena Pravilnika o postopkih za uveljavljanje pravic do družinskih prejemkov ( $v$ nadaljevanju 47. člen), s pomočjo zapisa 47. člena s sintakso propozicijske logike, logične dekompozicije ter preveritve semantične smiselnosti, lahko trdimo naslednje:

"Sedanja formulacija 47. člena je dvoumna, ker dopušča več možnih interpretacij, ki so vse logično pravilne."

"Sedanja formulacija 47. Člena $v$ vseh, sicer logično pravilnih, interpretacijah postavlja vsaj en pogoj za upravičenost do pravice tako, da le-ta ničesar ne omejuje, oz. da je le-ta brez funkcije."

"Pogoj, ki je sicer formuliran, vendar $v$ nobeni od možnih interpretacij ne vpliva na upravičenost do pravice, je prijavljenost na zavodu za zaposlovanje kot brezposelna oseba."

"Po vsebini še najbolj smiselna interpretacija 47. člena je po intuiciji najmanj verjetna."

Na podlagi vsega do sedaj povedanega, lahko trdimo še:

"Zapis besedila pravnega besedila s sintakso propozicijske logike, sklepanje s pomočjo njenih pravil ter uporaba tehnike logične dekompozicije nam lahko služijo kot sistematičen način za iskanje in dokazovanje semantično (ne)smiselnih interpretacij postavljenih pogojev. "

\section{Diskusija}

\subsection{Splošno priporočilo za navajanje pogojev}

Med reševanjem problema smo opazili, da hkratno navajanje pogojev z vezniki »in" ter "ali« povzroči kar nekaj nejasnosti in težav pri interpretaciji. Razlog za to je, ker sta v slovnici veznika »in« ter »ali« enakovredna. Tako nam $\vee$ primeru: $\quad a \vee b \wedge c$

lahko intuicija ponudi dve interpretaciji:

$$
\begin{aligned}
& (a \vee b) \wedge c, \\
& a \vee(b \wedge c),
\end{aligned}
$$


ki pa sta glede na pravila logike različni, pri čemer je pravilna le druga interpretacija. Ker se nekaterim intuitivno zdi pravilna ena interpretacija in drugim druga, pride do nesporazumov in dvoumnosti.

Podobno pride do nesporazumov ob uporabi negacije, ker pogosto ne vemo, na kaj se negacija nanaša. Lahko se nanaša samo na prvo sledečo izjavo:

$! a \vee b$,

ali ne več sledečih izjav v istem stavku:

$!(a \vee b)$,

kar pa zopet ni logično enako. $\vee$ primeru, da se negacija nanaša na več sledečih izjav, povezanih z veznikom "ali«, dobimo več negiranih pogojev, vendar povezanih z veznikom »in« (De Morganov teorem):

$!(a \vee b) \rightarrow ! a \wedge ! b$

in ne:

$!(a \vee b) \rightarrow ! a \vee ! b$

kot bi lahko intuitivno sklepali. To je še en primer, ko nas lahko naša intuicija zavede. Podobno velja, da je logično pravilno:

$!(a \wedge b) \rightarrow ! a \wedge ! b$

in ne:

$!(a \wedge b) \rightarrow ! a \vee ! b$.

Iz ravnokar povedanega lahko podamo splošno in enostavno priporočilo za navajanje pogojev pri pisanju pravnih besedil:

"Pri navajanju pogojev se je treba izogibati hkratnemu navajanju obligacijskih ter opcijskih pogojev. Jasno je tudi treba opredeliti, na kaj se nanaša negacija. Če se le da, naj se negacija nanaša le na eno izjavo."

\subsection{Predlog semantično smiselnega besedila 47. člena}

Če je obstoječi 47. člen semantično nesmiseln, se vprašamo, kako pa bi 47. člen potem moral biti zapisan, da bi bil semantično smiseln. 
Iztok Rakar, Domen Cukjati

Razlaga pravnih pravil s pomočjo propozicijske logike primer družinskih prejemkov

Pravilnik je ena od pravnih podlag za odločanje $\vee$ upravnem postopku $s$ področja socialne varnosti. Zakon o splošnem upravnem postopku (ZUP) ${ }^{10}$ kot enega od temeljnih načel določa načelo materialne resnice: „ $\vee$ postopku je treba ugotoviti resnično dejansko stanje in $v$ ta namen ugotoviti vsa dejstva, ki so pomembna za zakonito in pravilno odločbo« (1. odst. 8. člena). ${ }^{\text {"Temu us- }}$ trezno Zakon o starševskem varstvu in družinskih prejemkih (ZSDP) ${ }^{\mathbf{1 2}}$ določa, da "... mora vsakdo sporočiti centru dejstva in okoliščine oziroma vse spremembe, ki vplivajo na priznane pravice, njihovo višino in obdobje prejemanja ...« (102. člen).

Na podlagi teh dveh členov bi morali upravičenci vsak mesec sporočati tudi najmanjše spremembe, recimo $v$ svojih dohodkih, center za socialno delo ( $v$ nadaljevanju CSD) pa bi vsak mesec preračunaval višine priznanih pravic ter izdajal nove odločbe. Da bi se temu izognili, je pravilnik določil, da naj se preračunavanja izvajajo le enkrat na leto s podatki iz preteklega oz. predpreteklega leta in sicer tako, da se upošteva povprečna vrednost dohodkov. Tako 22. člen pravilnika določa, da »Upravičenci, ki že prejemajo otroški dodatek, vložijo vlogo za ponovno uveljavitev pravice do otroškega dodatka $v$ zadnjem mesecu veljavnosti odločbe ", 23. člen pa določa, da je "Skupni dohodek družine vsota vseh bruto dohodkov, ki so vir dohodnine, transfernih dohodkov in vseh drugih dohodkov vseh družinskih članov za isto koledarsko leto, ... ". Zato se odločbe v praksi praviloma izdajajo za obdobje enega leta.

Ravnokar opisana praksa pa je korektna le $v$ primeru, da je socialni položaj posameznika oz. družine $v$ trenutku odločanja o višini pravice vsaj približno enak kot $\vee$ preteklem oz. predpreteklem letu. Ker pa se socialni položaj posameznika $\vee$ tako dolgi dobi lahko drastično spremeni, je pravilnik to upošteval na ta način, da je določil, da se $v$ primeru velikih sprememb v višini dohodkov upošteva trenutno stanje, preračunano na celo leto. Ker se velike spremembe zgodijo ob nastopu službe po daljšem obdobju nezaposlenosti, 46. člen pravilnika določa:

"Če se je eden od vzdrževalcev družine zaposlil, se ... upošteva tudi plača vzdrževalca družine, ki se je zaposlil, tako da se višina bruto plače oziroma prejemka

10 Zakon o splošnem upravnem postopku (ZUP), Ur. I. RS, št. 80/1999, 70/2000, 52/2002, 73/2004, 22/2005-UPB1, 119/2005, 24/2006-UPB2, 105/2006-ZUS-1, 126/2007 in 65/2008.

11 Podr. v Androjna/Kerševan (2006, str. 98-103) ter Jerovšek (ur.) in Trpin (ur.) (2004, str. 80-85).

12 Zakon o starševskem varstvu in družinskih prejemkih (ZSDP), Ur. list RS, št. 97/2001, 76/2003, 110/2003-UPB1, 56/2005 Odl.US: U-I-137/03-23, 111/2005 Odl.US: U-I-31/04-14, 21/2006 Odl.US: U-I-116/03-22, 47/2006, 110/2006-UPB2, 114/2006-ZUTPG, 122/2007 OdI.US: U-I-11/07-45, 10/2008. 
Iztok Rakar, Domen Cukjati

Razlaga pravnih pravil s pomočjo propozicijske logike primer družinskih prejemkov

iz zaposlitve, ki ga je prejel v prvem mesecu zaposlitve, pomnoži s številom mesecev predvidene zaposlitve v tekočem letu ..."

Da bi upoštevali zrcalen primer, ko nekdo izgubi zaposlitev in dohodek po daljšem obdobju zaposlenosti, bi morali torej 47 . člen pravilnika zapisati na naslednji način:

"Da se dohodki iz bruto plač vzdrževalca družine $v$ preteklem letu ne vštevajo $\vee$ skupni dohodek družine, mora biti izpolnjeno, da je vzdrževalec družine izgubil zaposlitev, da ne prejema nadomestila, da ne prejema pokojnine in da ne prejema delnega plačila za izgubljen dohodek."

Prijavljenost na Zavodu za zaposlovanje pa je tako ali tako nujni pogoj za prejemanje nadomestila in tega dejstva ni potrebno pisati $\vee$ 47. člen.

Če sedaj zapišemo 47. člen s sintakso propozicijske logike, kot smo to storili $\vee 3$. poglavju, dobimo:

$$
(A \wedge ! B \wedge ! D \wedge ! E) \rightarrow ! F .
$$

Vidimo, da smo podali pet obveznih, torej z veznikom »in « povezanih pogojev. S tem smo tudi upoštevali splošno priporočilo za navajanje pogojev. Formulacija besedila je zato nedvoumna, saj nam kakršnakoli interpretacija vrne tako logično kot semantično enako izjavo.

\subsection{Primer iz prakse}

$\mathrm{Na}$ koncu poglejmo še, kakšne so posledice uporabe nejasnih pravil $v$ upravni praksi. $\vee$ konkretni zadevi je mati zapustila trg delovne sile, da bi varovala ter vzgajala več svojih predšolskih otrok. ${ }^{\mathbf{1 3}} \mathrm{Z}$ izgubo njenega celotnega dohodka se je močno spremenilo finančno stanje družine, ki po novem vsekakor ni tako, kot je bilo pred enim oz. dvema letoma. Mati je sporočila spremembo stanja na pristojni CSD, ki pa je otroške dodatke $v$ odločbi št. 1211565/2007-11 z dne 28.1.2008 zopet izračunal s podatki iz preteklega leta oz. ni upošteval dejstva, da se je finančni položaj družine močno spremenil.

V pritožbenem postopku je pristojni organ v odločbi št. 12103-54/2008/04 z dne 29.4.2008 vztrajal pri razlagi, ki jo je zastopal tudi CSD, in sicer da je prijavljenost na zavodu (izjava C) nujni pogoj za dodelitev pravice - čeprav smo v prispevku pokazali, da je ravno ta pogoj $v$ vsaki od možnih interpretacij brez

13 Taka odločitev temelji na dejstvu, da v okolici Ljubljane praktično ni prostih mest v javnih vrtcih. 
Iztok Rakar, Domen Cukjati

Razlaga pravnih pravil s pomočjo propozicijske logike primer družinskih prejemkov

funkcije. Besedilo je torej razlagal tako, kot da besedilo za prvim "ali« sploh ne obstaja, kar pa vsebino 47. člena seveda popolnoma spremeni. Napačna razlaga pogojev iz pravilnika je tako vodila $\vee$ napačno ugotavljanje dejanskega stanja in $s$ tem posledično $v$ kršitev načela materialne resnice $\vee$ upravnem postopku in končno $v$ izdajo nepravilne in nezakonite odločbe.

Razlogi za takšno razlago pristojnih organov so lahko različni ${ }^{\mathbf{1 4}}$, posledice nejasnih pravil za posameznike pa na podlagi prikazanega nedvomno zelo pomembne - od neposrednih finančnih do posrednih državljanskih $v$ smislu zbujanja dvoma $v$ pravno in socialno državo, še posebej če bi se izkazalo, da upravni organi $v$ enakih primerih odločajo različno. Te posledice nedvomno terjajo natančnejše spremljanje zakonodaje in prakse s tega področja.

\section{Zaključek}

Namen tega prispevka je bil na primeru iz prakse pokazati, da nam propozicijska logika lahko služi kot orodje za sistematično dokazovanje vsebinske (ne)smiselnosti določene strukture pogojev. Najprej smo zapisali besedilo s sintakso propozicijske logike, poiskali vse možne interpretacije besedila, med njimi izbrali vse, ki predstavljajo logično pravilne, vendar različne izjave ter za vsako od njih preverili ali predstavlja semantično smiselno formulacijo. Na ta način smo dokazali, da je sedanja formulacija besedila zapisana dvoumno ter vsebinsko nesmiselno, s tem pa smo tudi pokazali, da si pri analizi semantične smiselnosti postavljenih pogojev lahko pomagamo s propozicijsko logiko. $\mathrm{Na}$ koncu smo podali splošno priporočilo za navajanje pogojev, podali predlog nedvoumno zapisanega besedila ter pokazali, kakšne so $v$ praksi posledice napačne formulacije za določeno skupino državljanov in za temeljna pravna načela.

Prihodnja raziskava bi šla lahko $v$ smeri iskanja sredstev za avtomatično preverjanje oz. dokazovanje semantične smiselnosti postavljenih pogojev. Obstajajo namreč orodja za formalni zapis znanja oz. ontologij (Gomez et al., 2004), npr. OWL (W3C, 2008), ki omogočajo zapis znanja, npr. o stanjih, v katerih se lahko znajdejo posamezniki, ter preverjanje vsebinske skladnosti oz.

14 Iskanje razlogov za odločitev, ki naj bi bili "skriti" za pravnimi razlogi, ki izhajajo iz obrazložitve pravnih aktov, vodi $v$ sporne in težko dokazljive domneve - od nezavedne napačne razlage na eni strani do zavestne napačne razlage z namenom diskriminiranja določene skupine državljanov na drugi strani. 
Iztok Rakar, Domen Cukjati

Razlaga pravnih pravil s pomočjo propozicijske logike primer družinskih prejemkov

neskladnosti zapisanega znanja. Pri tem bi lahko uporabili tudi izsledke raziskav s področja modeliranja normativnih aktov (Berčič, 2006).

Mag. Iztok Rakar je na Pravni fakulteti Univerze v Ljubljani diplomiral leta 1998 s področja upravnega prava in se leto kasneje zaposlil kot sodniški pripravnik na Višjem sodišču v Ljubljani, leta 2000 pa kot asistent za upravnopravno področje na Fakulteti za upravo. Leta 2001 se je vpisal na podiplomski študij javne uprave na ljubljanski Pravni fakulteti, kjer je leta 2004 tudi magistriral. Ima opravljen strokovni izpit za zaposlene v državni upravi ter pravosodni izpit (državni pravniški izpit). Leta 2006 je postal doktorski kandidat na Pravni fakulteti Univerze $v$ Ljubljani z naslovom doktorske disertacije Vključevanje javnosti $v$ delovanje izvršilne veje oblasti pri sprejemanju splošnih pravnih aktov $v$ Republiki Sloveniji.

Domen Cukjati je diplomiral leta 2001 na Fakulteti za matematiko in fiziko, smer fizika. Od leta 2005 je doktorski študent na Ekonomski fakulteti, program Poslovna informatika. V letih 2002 - 2005 zaposlen v C3M d. o. o. kot razvijalec računalniškega programa za optimizacijo in kot sodelavec na raziskovalnih projektih Evropske Komisije (5. in 6. okvirni program). Od leta 2005 - 2008 je bil redno zaposlen na Fakulteti za upravo kot asistent in raziskovalec na katedri za Organizacijo in Informatiko.

\section{Literatura in viri}

- $\quad$ Androjna, V., Kerševan, E. (2006): Upravno procesno pravo. GV Založba, Ljubljana.

- Berčič, B. (2006): Modeliranje delno strukturiranih odločitvenih situacij na podlagi modela normativnih aktov. Doktorska disertacija. Univerza v Ljubljani, Ekonomska fakulteta.

- Gomez, P., A., Fernandez, L., M \& Corcho, O. (2004): Ontological Engineering with examples from the areas of Knowledge Management, e-commerce and the Semantic Web. ISBN: 1-85233-551-3.

- Jerovšek, T. (ur.), Trpin,G. (ur.) (2004): Zakon o splošnem upravnem postopku s komentarjem. Inštitut za javno upravo pri Pravni fakulteti v Ljubljani, Ljubljana.

- Layman, A. (1957): Symbolic Logic: A Razor-Edged Tool for Drafting and Interpreting Legal Documents. Yale Law Journal, Vol.66:833, 1957.

- Love, N., Genesereth, M., R. (2005): Computational Law. In Proceedings of the International Conference on Artificial Intelligence and Law, Bologna, Italy, 2005.

- Mendelson, E. (1997): Introduction to Mathematical Logic. Fourth Edition. International Thomson Publishing, 1997. 
Iztok Rakar, Domen Cukjati

Razlaga pravnih pravil s pomočjo propozicijske logike primer družinskih prejemkov

- Odločba Ustavnega sodišča RS, št. U-I-220/03-20 z dne 13. 10. 2004. http://odlocitve.usrs.si/usrs/us-odl.nsf/o/D000E94AED6A15C9C125717200288D56.

- Pravilnik o postopkih za uveljavljanje pravic do družinskih prejemkov. Ur. list RS, št. 31/2008, 15/2007, 116/2003.

- Rakar, I. (2006): Etika, korupcija in pravo. V: Vlaj, S. (ur.) (2006): Etično upravljanje občin: z modelom kodeksa. Ljubljana, Inštitut za lokalno samoupravo pri Fakulteti za upravo.

- $\quad$ Rissland, E., L., Ashley, K., D. and Loui, R., P. (2003): Al and law: a fruitful synergy. Artif. Intell., 150(1-2):1-15.

- Sachs, M. (ur.) (2003): Grundgesetz: Kommentar (3. Aufl.). C. H. Beck, München.

- Schneider, E. (1999 / 1991): Logika za pravnike (Logik für Juristen). Cankarjeva založba, Ljubljana.

- Šturm, L. (ur.) (2002): Komentar Ustave Republike Slovenije. Fakulteta za podiplomske državne in evropske študije, Ljubljana.

- Šuster, D.(2000): Simbolna logika. Maribor: Pedagoška fakulteta.

- Tomažič, A. (2008): e-Justice is based on e-Law. Conference presentation, e-Justice \& e-Law 2008 conference. http://www.ejustice2008.si/en/wpcontent/uploads/2008/06/tomazic_conference.doc

- Ustave Republike Slovenije, Ur.I. RS, št. 33I/1991-I, Ur.I. RS, št. 33I/1991-I, 42/1997, 66/2000, 24/2003, 69/2004, 69/2004, 69/2004, 68/2006.

- Zakon o splošnem upravnem postopku (ZUP), Ur. I. RS, št. 80/1999, 70/2000, 52/2002, 73/2004, 22/2005-UPB1, 119/2005, 24/2006-UPB2, 105/2006-ZUS-1, 126/2007 in $65 / 2008$.

- Zakon o starševskem varstvu in družinskih prejemkih (ZSDP), Ur. list RS, št. 97/2001, 76/2003, 110/2003-UPB1, 56/2005 Odl.US: U-I-137/03-23, 111/2005 Odl.US: U-I-31/0414, 21/2006 Odl.US: U-I-116/03-22, 47/2006, 110/2006-UPB2, 114/2006-ZUTPG, 122/2007 Odl.US: U-I-11/07-45, 10/2008.

- W3C (2008). OWL Working Group. Dobljeno 15.7.2008 na: http://www.w3.org/2007/OWL/wiki/OWL_Working_Group 
SUMMARY

\section{INTERPRETATION OF LEGAL RULES WITH PROPOSITIONAL LOGIC - THE CASE OF FAMILY BENEFITS}

Conditions determining whether an individual is eligible to a certain right or not are a common source of ambiguity and confusion in legal texts. Formulations indicating obligatory and optional conditions, which are commonly written partly in affirmative and partly in negative forms, are most problematic. The purpose of this paper is to analyse Article 47 of the Rules on procedures for claiming the right to family benefits, and show that propositional logic can be used to systematically prove contentrelated (un)clarity of a particular structure of conditions. Firstly, we rewrite Article 47 with the syntax of propositional logic, and then look for all possible interpretations of the text, among which we select those that are logically correct yet logically different statements and test them to see if they present formulations with semantic sense. In this way, we prove that the existing text of the article is vague and irrelevant in terms of content. In the end, we provide a general recommendation on how to better phrase conditions and, by way of a practical example, illustrate what impact the consequences may have if conditions are formulated incorrectly.

The text of Article 47 reads as follows: "If one of family beneficiaries loses employment and does not receive allowance, but is registered the Employment Service of Slovenia (ESS) as an unemployed person, or does not receive a pension or partial allowance for lost income, his or her income from gross salaries in the previous year is not included in the total family income."

The following are the conclusions of a detailed analysis of the article in question after applying the syntax of propositional logic, logical decomposition and verification of semantic sense:

"The existing formulation of Article 47 is ambiguous for it allows several interpretations which are all logically correct."

"In all of its interpretations, which are otherwise logically correct, the existing formulation of Article 47 sets at least one condition for the entitlement to a right so that the latter does not limit anything and is therefore functionless." 
Iztok Rakar, Domen Cukjati

Razlaga pravnih pravil s pomočjo propozicijske logike primer družinskih prejemkov

"The condition, which is indicated, but does not have any impact on the eligibility to a right in any of the given interpretations, is the status of being registered as an unemployed person at the ESS."

"The interpretation of Article 47 that makes most sense in terms of content is least likely in terms of intuition."

In view of the above, the following may also be asserted:

"Notation of a legal text with the syntax of propositional logic, deduction with inference from its rules and use of the technique of logical decomposition are tools facilitating a systematic approach to searching and verification of semantically (un)ambiguous interpretations of conditions."

While looking for a solution to the problem, it has become evident that parallel indication of conditions linked with connectors "and" and "or" causes vagueness and makes interpretation problematic. The reason for that are the connectors "and" and "or" which join clauses of grammatically equal importance and rank in the Slovenian language. Considering the $a \vee b \wedge c$ statement, one can, by intuition, make two interpretations which are different in terms of the rules of logic whereby only one of the two is correct. People instinctively believe that either one or the other interpretation is correct, which causes misunderstanding and leads to ambiguity. Negation also has the same effect as its reference is often unclear. It may refer to the closest following statement or several following statements in the same clause, which again presents logical inequality. And this leads us to a simple and general recommendation for specifying conditions in a legal text:

"When stating conditions, parallel indication of obligatory and optional criteria should be avoided. Further, it should be clear to which chunk of the text negation refers to. If possible, negation should refer to one statement at a time."

In view of the above, Article 47 of the Rules should be written as follows: "Beneficiary's gross salaries of the previous year shall not be included in the total family income if it has been established that a family beneficiary has lost his/her job, he/she does not receive allowance, he/she does not receive pension and he/she does not receive partial payment for the lost income." The fact that a person has to be registered at the ESS is a necessary condition that has to be fulfilled nonetheless in order to receive an allowance, and so does not need to be listed as a condition in Article 47. As we have seen, five compulsory conditions have been listed and connected with "and". The proposed general recommendation has 
thus been taken into consideration. As a result, the text is straightforward and no matter what interpretation we take, it will yield a logically and semantically equal statement.

Eventually, let us look at the consequences caused by unclear rules in administrative law practice. A mother left the labour market to look after several of her pre-school children. As she no longer earned income, the financial situation of the family changed dramatically with the current situation definitely worse than that of one or two years ago. The mother reported her change of status to the competent administrative unit which made a calculation for child support on the basis of the previous year without taking into consideration the changed financial situation of the family.

In the complaint procedure the competent administrative authority supported the decision of the first instance authority, claiming that one's registration of status at the ESS is a necessary condition for granting the right. This paper, however, has proven that this particular condition is irrelevant to all possible interpretations. The authority had interpreted the text as if there had been no wording following the first "or", which of course changed the contents of Article 47 completely. Thus, erroneous interpretation led to false establishment of facts and, consequently, violation of the principle of substantive truth in the administrative procedure, followed by issuing an incorrect and illegal decision.

There are several reasons why the authorities interpreted the rules in the above manner, however, the example shows that unclear rules undoubtedly have important consequences for individuals, causing direct financial harm as well as indirectly influencing their civil awareness in terms of their losing confidence in the rule of law and welfare state, more so if it turns out that authorities have adopted different decisions in similar cases. It is therefore absolutely necessary that legislation and practice from the relevant field are given closer attention. 